\title{
Research Paper: Investigating the Relationship Between Sensory Processing Sensitivity and Life Style With Stress in Patients With Irritable Bowel Syndrome
}

\author{
Bahareh Ghorbani Taghlidabad $^{1 *}$ (D), Reza Tasbihsazan Mashhadi ${ }^{1}$ (D)
}

1. Department of Psychology, Faculty of Humanities, Urmia Branch, Islamic Azad University, Urmia, Iran.

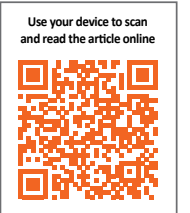

Cltation: Ghorbani Taghlidabad, B., \& Tasbihsazan Mashhadi, R. (2018). Investigating the Relationship Between Sensory Processing Sensitivity and Life Style With Stress in Patients With Irritable Bowel Syndrome. Journal of Practice in Clinical Psychology, 6(4), 239-248. http://dx.doi.org/10.32598/jpcp.6.4.239

doi : http://dx.doi.org/10.32598/jpcp.6.4.239

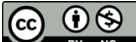

Funding: See Page 245

Article info:

Received: 02 Apr 2018

Accepted: 29 Aug 2018

Available Online: 01 Oct 2018

\section{Keywords:}

Irritable bowel syndrome, Life style assessment, Sensory processing sensitivity, Structural equation modeling, Perceived stress

\section{ABSTRACT}

Objective: Irritable Bowel Syndrome (IBS) is a chronic, disabling, and functional disorder of the gastrointestinal tract in the absence of identifiable structural disorder. The present study aimed to investigate the relationship between sensory processing sensitivity and life style with perceived stress considering mediating role of duration of syndrome in patients with IBS using structural equation modelling.

Methods: In this correlational study, 170 IBS patients (93 women, 77 men) recruited via convenient sampling method from gastrointestinal clinics in Urmia. The relevant data were collected by means of high sensory processing scale, perceived stress scale, and Miller-Smith life style assessment inventory. The obtained data were analyzed using correlation coefficient, and structural equation modelling.

Results: Duration of syndrome had a mediator role between sensory processing sensitivity, and perceived stress in patients with IBS (path coefficient reported $0.24, \mathrm{P}<0.00$, Chi-square value: $\chi^{2}=0.01, \mathrm{P}<0.001$, goodness of fit indices $(\mathrm{CFI}=0.99, \mathrm{NFI}=0.98)$ and standardized error (0.05). The same mediator role of duration of syndrome was not reported in relation between life style and perceived stress (path coefficient $=0.06, \mathrm{P}<0.001$ ). Sensory processing, life style, and duration of syndrome explained $50 \%$ of perceived stress variance.

Conclusion: Results indicate that sensory processing sensitivity may be a temperamental disposition that interacts meaningfully with environmental factors in chronic illnesses. The relationship between sensory processing sensitivity and stress in an illness is best explained considering the possibility of contributory factors.

\section{* Corresponding Author:}

Bahareh Ghorbani Taghlidabad, MSc.

Address: Department of Psychology, Faculty of Humanities, Urmia Branch, Islamic Azad University, Urmia, Iran.

Tel: +98 (939) 8513346

E-mail: bahareghorbani0@gmail.com 


\section{Highlights}

- Sensory processing sensitivity has an indirect effect on perceived stress in patients with irritable bowel syndrome.

- Adding the duration of syndrome makes the indirect effect meaningful.

\section{Plain Language Summary}

In this study, we tried to find pathways between sensory possessing sensitivity and lifestyle with perceived stress in patients with irritable bowel syndrome. Surprisingly, our study results revealed that patients with highly sensitive personalities are not prone to experience higher amount of stress unless in the presence of a chronic illness. The same report did not come out about lifestyle relation to the model. These findings are intriguing data supporting that highly sensitive personality might not impose patients to the stress, but it effectively combines with external factors such as duration of syndrome and plays an effective indirect role. Sensory processing sensitivity is a relatively new construct and its role in chronic illnesses is still unclear. Considering these data, indirect effects of temperamental variables might play significant role in the chronic physical illnesses.

\section{Introduction}

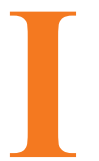

rritable Bowel Syndrome (IBS) is defined by abdominal pain or discomfort and altered bowel habits, including diarrhea, constipation, as well as additional symptoms such as bloating, gas, swelling, and urgency (Mayer, Naliboff, Chang \& Coutinho, 2001). IBS is the most prevalent gastrointestinal disorder worldwide, and the prevalence of it ranges from $7 \%$ to $21 \%$, which strongly impacts the quality of life, social function, work productivity, and imposes substantial costs to health care services (Almquist, Tornblom \& Simren, 2016; Lovell \& Ford, 2012). Although several pathophysiologic mechanisms, including psychological factors are reported for IBS via central nervous system (Chey, Kurlander \& Eswaran, 2015; Meleine \& Matricon, 2014), the exact etiology of IBS remains unclear (Sood, Law, \& Ford, 2014).

Various studies established that psychological stress modifies gastrointestinal functions including motility and sensations (Dickhaus et al., 2003; Drossman et al., 1990). Most recent studies using positron emission tomography scanning and functional MRI illustrated irregularities in brain performances in patients with IBS, compared to the controls (Naliboff et al., 2001; Mertz et al., 2000). Idiosyncrasies presented in the anterior cingulate cortex, probably have a crucial role in the evolution of attention to an irritating stimuli, the distastefulness related to a painful stimuli, and emotional reaction to a painful stimuli (Wood, 2001).
Sensory processing of information is probably the fundamental psychological factor explaining how individuals proceed and recognize the environment. Sensory processing sensitivity refers to one's choice of strategy to transmit and process sensory information in the brain. Sensory processing sensitivity is a new concept, illustrating a proneness to process hardly, and explosively diverse information like arts, caffeine, other's mood, hunger, and pain (Aron \& Aron, 1997)

Sensation provides the only known form of communication between individual and environment, and evidence is growing that individuals process sensory information in different ways. Some people are more sensitive to sensory information than the others (Aron \& Aron, 1997; Dunn, 2001). Sensory processing style is related to the construct of behavioral inhibition, shyness, and introversion. Moderate correlations are reported between sensitive sensory processing style with introversion, and emotionality (Aron \& Aron, 1997; Carver \& White, 1994; Gray, 1981; Eysenck, 1991; Kagan, 1994).

Studies suggest that introversion and emotionality are the most likely evident expositions of sensitive sensory processing style. A persons' sensory processing style might be a considerable regulating factor in their character and temperament (Aron \& Aron, 1997). Research using Aron and Aron (1997) construct of sensory processing, reports that sensitive people are more likely to experience anxiety disorders (Gannon, Banks, Shelton \& Luchetta, 1989).

In several studies, sensory processing sensitivity was related to mental health, stress, and physical symptoms. 
It was also related to avoidant personality disorder and borderline personality disorder, parental bonding, anxiety, depression, social phobia, and work related variables (Ahadi \& Basharpoor, 2010; Benham, 2006; Meyer, Ajchenbrenner \& Bowles, 2005; Liss, Timmel, Baxley \& Killingsworth, 2005; Hofmann \& Bitran, 2007; Neal, Edelmann \& Glachan 2002; Evers, Rasche $\&$ Schabracq, 2008). Most of these research studies report that sensory processing sensitivity is related to intense stress, because majority of them indicate a correlation between high sensory processing and symptoms associated with stress or anxiety.

Lifestyle is proposed as one of the important determining elements in people's general health, globally. (Egger, Binns \& Rossner, 2009). Moreover, acquiring several preventive lifestyle behaviors has a great beneficial health effects. There is growing evidence for the value of these protective behaviors, in health promotion and health monitoring. In summary, considerable evidence demonstrates that stress may exacerbate symptoms of IBS, and sensory processing sensitivity is associated with higher stress.

Despite the important role of lifestyle in chronic diseases, researchers disregarded investigating sensory processing sensitivity and lifestyle in relation to perceived stress in patients with IBS, considering the mediating role of duration of syndrome, and with the use of Structural Equation Modeling (SEM). Therefore, this study aimed to investigate the relationship between sensory processing sensitivity and lifestyle and perceived stress, considering the mediating role of duration of symptoms in patients with IBS using SEM.

\section{Methods}

This was a cross-sectional study, approved by the local Ethics Committee. Over the course of 10 months (August 2015 to May 2016), 210 IBS patients were selected through convenience sampling method, and 170 (93 women and 77 men) of them agreed to participate in the study. All study participants gave a consent form, approved by the Ethics Committee of the University. The subjects aged between 18 and 58 years. The mean \pm SD age of the samples was $34.38 \pm 8.71$ years. All participants who suffered from bowel symptoms suggestive of IBS were referred for gastroenterology examinations. After taking medical history and performing physical examination along with sigmoidoscopy, and colonoscopy, the patients were diagnosed according to the Rome criteria for IBS. The patients with psychotic disorders or a current or previous diagnosis of bowel disease (e. g. ulcerative colitis) were excluded from the study.

Aron and Aron Highly Sensitive Person (HSP) is a Likert-type scale that involves an extensive set of components associated with sensitivity including ' are you easily overwhelmed by strong sensory input?" and "'do you have a rich, complex inner life?" Response categories range from 1 (not at all) to 5 (extremely often) (Aron \& Aron, 1997). The reliability was $\alpha=0.87$, in the original investigation (Smolewska, McCabe \& Woody, 2006). Internal consistency was $\alpha=0.35$ in the present study.

Cohen Perceived Stress Scale (PSS) with 7 positive items and 7 negative items is a 14-item, 5-point Likerttype scale that asks interviewee "'in the last month, how often you..." and includes elements such as 'felt nervous and stressed?" Scores range from 0 (never) to 4 (very often). The reliability of PSS is reported as $\alpha=0.85$ (Cohen, Kamarch \& Mermelstein, 1983) and $\alpha=0.79$ in the present study. Total scores ranged from 0 to 56 .

Miller-Smith Lifestyle Assessment Inventory (LSI) consists of 20 items with a 5-point Likert-type scale that asks respondents how often the related items are applies to them, e. g. "I eat at least one hot balanced meal a day" and "I give and receive affection regularly”. Response choices range from 1 (always) to 5 (never). Total scores range from 20 to 100 (Miller \& Smith, 1988). Miller and Smith (1988) reported the reliability as $\alpha=0.85$. The AMOS (version 22.0, Chicago: IBM SPSS) was applied to analyze research data by $\operatorname{SEM}(\mathrm{P}<0.001)$.

\section{Results}

The Chi-square goodness-of-fit test is commonly used and highly sensitive to sample size and data normality (Hoyle, 1995). The present study used Non-Normed Fit Index (NNFI) (Joreskog \& Sorbom, 1989), goodness of fit index, adjusted goodness of fit index, standardized root mean squared residual as absolute fit indices, and Chi-square with degrees of freedom $\chi^{2} / \mathrm{df}$, parsimony fit index, and root mean square error of approximation, were applied as parsimonious fitness indices.

Table 1 presents descriptive indices of variables, including mean, standard variance, skewness and kurtosis. Concerning the application of causal modeling, the distribution of variables must be normal (Tucker $\&$ Lewis, 1973). The absolute value of skewness and kurtosis should not exceed 3 and 10, respectively (Bentler, 1989). According to Table 1 , the absolute value of 
Table 1. Descriptive indices of research variables

\begin{tabular}{cccc}
\hline Variable & Mean \pm SD & Skewness & Kurtosis \\
\hline Ease of excitement & $40.06 \pm 6.49$ & 0.17 & 0.24 \\
Aesthetic sensitivity & $22.83 \pm 5.35$ & -0.02 & -0.13 \\
\hline Low sensory threshold & $19.07 \pm 5.27$ & 0.20 & -0.73 \\
Lifestyle & $44.01 \pm 17.48$ & 0.48 & -0.90 \\
\hline Duration of syndrome & $5.20 \pm 3.92$ & 0.63 & 0.54 \\
\hline Perceived negative stress & $16.60 \pm 7.85$ & 0.44 & -0.41 \\
\hline Perceived positive stress & $13.83 \pm 6.89$ & 0.59 & -0.22 \\
\hline
\end{tabular}

skewness and kurtosis for all variables is $<1$. Therefore, the assumption of causal modeling means that univariate normality is established.

Table 2 indicates correlation matrix of research variables. According to Table 2, the relationship between ease of excitement, aesthetic sensitivity, lifestyle, and duration of syndrome, and perceived negative stress is positive and significant $(\mathrm{P}<0.01)$. There is no significant correlation between low sensory threshold and perceived negative stress $(\mathrm{P}<0.05)$. Mardia's normalized multivariate kurtosis measure was used to investigate multivariate normality. The value in the present study was 4.66, which is less than 63 (Teo \& Noyes, 2014).

In Table 3, indices of absolute, comparative, and parsimonious fit indices are separately reported. The goodness of fit was evaluated by the following statistics: GFI $(>0.90)$ and Adjusted Goodness of Fit Index (AGFI) to measure the fit between the hypothesized model and the observed covariance matrix (Table 3). Moreover, Standardized Root Mean Squared Residual (SRMR) as absolute fit indices at 90\% confidence interval $(<0.08)$ was used (Cole, 1987; Mulaik et al., 1989). Comparative Fit Index $(>0.90)$, and normed fit index $(>0.90)$, and non-normed fit index $(>0.90)$ were developed as comparative fit indices. Chi-square on freedom degree $3>\chi^{2} / \mathrm{df}<2$ was administrated

Obtained values in this research are at an acceptable level of fitness. According to the Table 3, all indices of fitness are satisfactory and the tested model represents appropriate fitness with collected data. Figure 1 illustrates the tested model of the research. According to Figure 1, high sensory processing, lifestyle, and duration of syndrome, collectively explain $50 \%$ of perceived stress variance. High sensory processing and lifestyle also predicate only $30 \%$ of changes of duration of syndrome.

Table 2. Correlation matrix of research variables

\begin{tabular}{|c|c|c|c|c|c|c|c|c|}
\hline No. & Variable & 1 & 2 & 3 & 4 & 5 & 6 & 7 \\
\hline 1 & Ease of excitement & 1 & & & & & & \\
\hline 2 & Aesthetic sensitivity & $0.34 *$ & 1 & & & & & \\
\hline 3 & Low sensory threshold & $0.23 *$ & $0.38^{*}$ & 1 & & & & \\
\hline 4 & Life style & $0.14^{* *}$ & $0.27^{*}$ & $0.12^{* *}$ & 1 & & & \\
\hline 5 & Duration of syndrome & $0.21 *$ & $0.50 *$ & $0.16^{* *}$ & $0.27^{*}$ & 1 & & \\
\hline 6 & Perceived negative stress & $0.21^{*}$ & $0.31^{*}$ & $0.13^{* *}$ & $0.45^{*}$ & $0.54^{*}$ & 1 & \\
\hline 7 & Perceived positive stress & $0.15^{* *}$ & $0.34^{*}$ & $0.09 * *$ & $0.45^{*}$ & $0.51^{*}$ & $0.77^{*}$ & 1 \\
\hline
\end{tabular}


Table 3. Goodness of fit indices for tested model of research

\begin{tabular}{ccccc}
\hline & Index & GFI & AGFI & SRMR \\
Absolute fitness indices & Obtained value & 0.98 & 0.96 & 0.03 \\
& Acceptable limit & $>0.90$ & $>0.80$ & $<0.05$ \\
& Index & CFI & NFI & NNFI \\
$\begin{array}{c}\text { Comparative fitness } \\
\text { indices }\end{array}$ & Obtained value & 0.99 & 0.98 & 0.99 \\
& Acceptable limit & $>0.90$ & $>0.90$ & $>0.90$ \\
& Index & $\chi^{2} / \mathrm{df}$ & PNFI & RMSEA \\
Adjusted fitness indices & Obtained value & 0.01 & 0.66 & 0.71 \\
& Acceptable limit & $<3$ & $>0.60$ & $<0.08$ \\
\hline
\end{tabular}

Abbreviations: CFI: Comparative Fit Index; AGFI: Adjusted Goodness of Fit Index; SRMR: Standardized Root Mea Square Residual; NFI: Normed Fit Index; NNFI: Non-Normed Fit Index; $\chi^{2}$ : Chi-square; PNFI: Parsimony Normed Fit Index; RMSEA: Root Mean Square Error of Approximation

Table 4 presents the results of direct effects of variables. According to the Table 4, the direct effect of high sensory processing on perceived stress, which is 0 in accordance with $t$ statistic, is not significant $(\mathrm{P}<0.001)$. However, the direct effect of lifestyle on perceived stress, in accordance with $t$ statistic, is positive and significant $(\mathrm{P}<0.001)$. One characteristic of structural equation modeling is to measure the indirect effects of variables on each other. This characteristic empowers researchers to investigate the mediating role of variables in a given model.

Bootstrapping method was used to determine significance of the indirect effect of high sensory processing and lifestyle on perceived stress. Bootstrapping in Amos program, evaluates the sample distribution of estimated

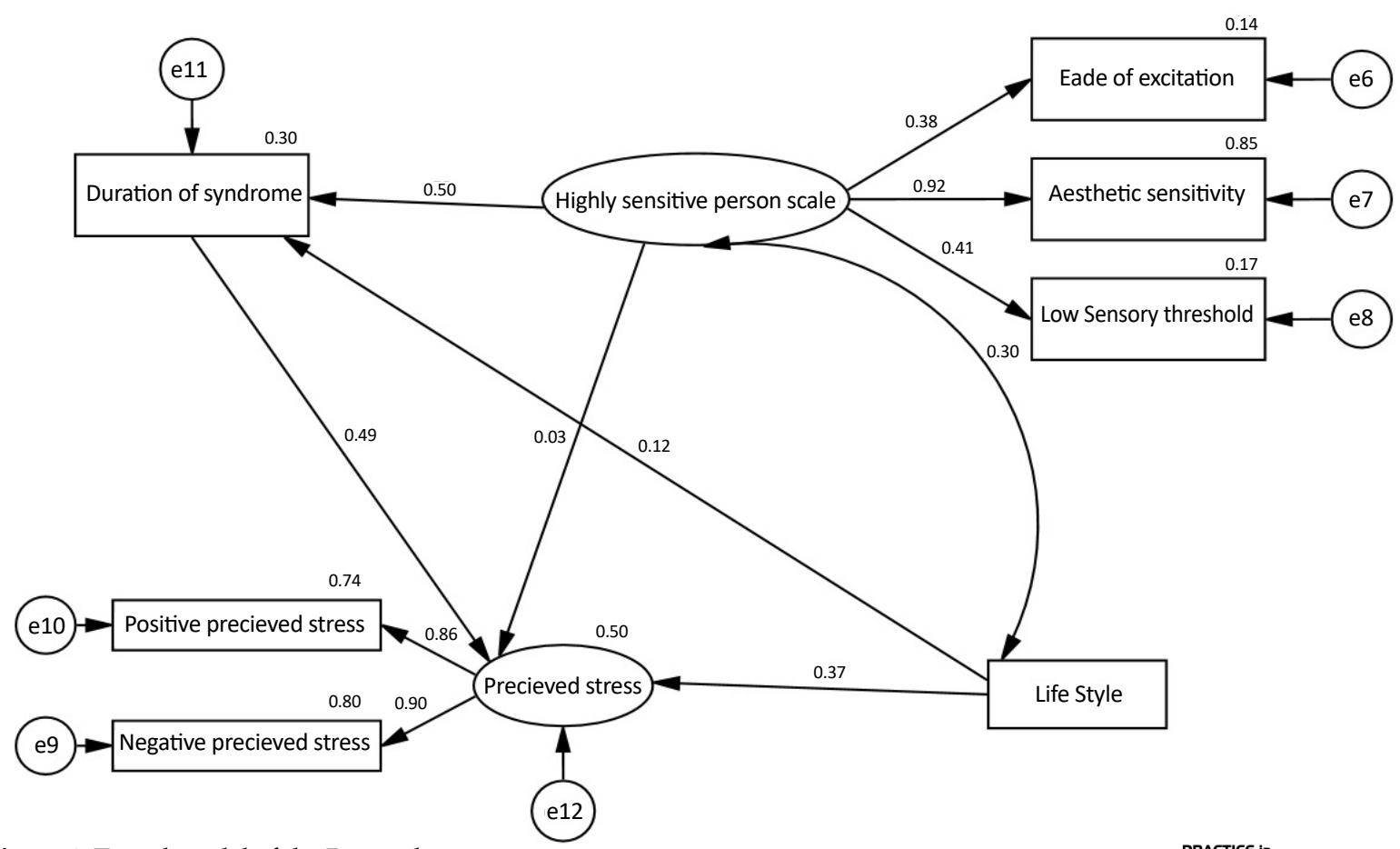

Figure 1. Tested model of the Research 
Table 4. The results of direct effects

\begin{tabular}{|c|c|c|c|c|c|c|}
\hline Path & & $\begin{array}{l}\text { Parameter } \\
\text { Estimation }\end{array}$ & $\begin{array}{c}\text { Path } \\
\text { Coefficient }\end{array}$ & $\begin{array}{l}\text { Estimation } \\
\text { Standard Error }\end{array}$ & $\begin{array}{c}\mathbf{t} \\
\text { Statistic }\end{array}$ & Sig. \\
\hline \multirow{3}{*}{$\begin{array}{c}\text { On the perceived stress } \\
\text { of }\end{array}$} & $\begin{array}{l}\text { Highly sensory } \\
\text { processing }\end{array}$ & 0.08 & 0.03 & 0.24 & 0.32 & 0.74 \\
\hline & Lifestyle & 0.15 & 0.37 & 0.03 & 5.58 & 0.001 \\
\hline & Duration of syndrome & 0.87 & 0.49 & 0.14 & 6.21 & 0.001 \\
\hline \multirow{2}{*}{$\begin{array}{l}\text { On duration of } \\
\text { syndrome from }\end{array}$} & $\begin{array}{l}\text { Sensory processing } \\
\text { sensitivity }\end{array}$ & 0.81 & 0.50 & 0.20 & 3.97 & 0.001 \\
\hline & Lifestyle & 0.03 & 0.12 & 0.02 & 1.54 & 0.12 \\
\hline
\end{tabular}

Table 5. Indirect effects of high sensory processing and lifestyle on perceived stress

\begin{tabular}{|c|c|c|c|c|c|}
\hline \multirow{2}{*}{ Variable } & \multirow{2}{*}{$\begin{array}{c}\text { Path } \\
\text { Coefficient }\end{array}$} & \multirow{2}{*}{$\begin{array}{c}\text { Estimation Standard } \\
\text { Error }\end{array}$} & \multirow{2}{*}{ Sig. } & \multicolumn{2}{|c|}{ Limit } \\
\hline & & & & Lower & Upper \\
\hline $\begin{array}{l}\text { Highly sensory } \\
\text { processing }\end{array}$ & 0.24 & 0.07 & 0.004 & 0.15 & 0.39 \\
\hline Lifestyle & 0.06 & 0.04 & 0.09 & 0.003 & 0.14 \\
\hline
\end{tabular}

parameters and related standard error. Such evaluation is useful for determining parameters resistance under assumptions of multivariate normality or poor model edition and comparison of substitute models and estimation method. Thus, bootstrapping or self-regulating was used to obtain the related estimations of main parameters of structural equation model (Cheung and Lau, 2007).

According to Table 5, the indirect effect of high sensory processing on perceived stress is significant $(\mathrm{P}<0.001)$, although same situation is not reported about lifestyle $(\mathrm{P}<0.001)$. Therefore, reports indicate that the duration of syndrome has a mediating role, in sensory processing sensitivity, in relation with perceived stress.

\section{Discussion}

The current study was designed to investigate the direct and indirect effects between sensory processing sensitivity and lifestyle with perceived stress by considering the mediating role of the duration of syndrome, with the use of structural equation modeling. The fit indices for the model were reported as excellent. High sensory processing, lifestyle, and the duration of syndrome, collectively explained $50 \%$ of perceived stress variances, which is consistent with the results of previous studies (Benham, 2006; Gerstenberg, 2012; Boyce et al., 1995; Gannon et al., 1989).
The indirect effect of high sensory processing was reported on perceived stress in patients with IBS. Thus, patients with high sensory processing are not more prone to excessive stress, compared to other IBS patients with lower sensory processing, unless the mediating role of duration of syndrome, is present. These results disagree with some previous studies, including Chey et al. (2015), Meleine and Martin (2014), Dikhaus et al. (2003), and Drossman et al. (1990).

The duration of syndrome plays a mediating role in relation with high sensory processing and perceived stress. However, according to the results, it does not affect the relationship between lifestyle and perceived stress. Furthermore, the duration of syndrome does not play a mediating role on the relationship between lifestyle and perceived stress. Therefore, some intriguing relationships between sensory processing, lifestyle, perceived stress, and the mediating role of the duration of syndrome were revealed.

Sensory processing sensitivity offers a functional setting of how inherent and innate components may interact with physical illnesses to produce psychological problems. Although sensory processing sensitivity is not usually measured in clinical settings, the mediating factors including the duration of a syndrome or an illness, may provide important information in understanding why certain individuals are prone to excessive 
and intense stress or other psychological difficulties in chronic illnesses (Aron \& Aron, 1997).

However, sensory processing is a feature that needs more explanation. One limitation to study was that the results reported in this study are based on a sample derived from convenience sampling method, and further studies using other sampling methods are required to support the validity of our findings. Also, results of this study relies on cross-sectional data, which could be confirmed through longitudinal methodology. Sensory processing sensitivity was considered an inherited variable. Future research would be useful to better understand the mediating role of other variables on sensory processing sensitivity among patients suffering from IBS and later psychological outcomes, and to evaluate whether highly sensory processing has a direct effect on psychological outcome of a chronic illness or not.

This study supports the indirect effect of high sensory processing sensitivity assessed by HSP scale on perceived stress, which was imposed via the duration of syndrome in patients with IBS. The duration of syndrome has a mediating role in sensory processing sensitivity in relation with perceived stress in patients with IBS, but the same mediating role was not true about the relationship between lifestyle and perceived stress. To our knowledge in the presence of high sensory processing in patients with IBS, they are not prone to experience excessive perceived stress without considering mediating role of duration of syndrome. Hence, it might be inferred that duration of syndrome modulates the relationship between sensory processing sensitivity and stress regardless of other contributory factors. Thus, it is important to assess the mediating factors contributing to illness in IBS patients, in order to prepare appropriate therapeutic plans.

The indirect effect of high sensory processing was reported on perceived stress in patients with IBS. Therefore, patients with high sensory processing are not more prone to experience excessive stress compared to other IBS patients with lower sensory processing, except for the presence of mediating role of some extra contributory factors like the duration of syndrome. Chronic illnesses might change patients' perception and attitudes towards their situation, and they might exaggerate or overestimate current stress of their life. Developing a treatment plan requires implementing these factors to avoid further drawbacks.

\section{Ethical Considerations}

\section{Compliance with ethical guidelines}

All the participants were given informed consent forms with an attached file explaining confidentiality, their right to withdraw, and debrief. This research was approved by local ethics committee.

\section{Funding}

This research did not receive any specific grant from funding agencies in the public, commercial, or not-forprofit sectors.

\section{Conflict of interest}

The authors certify that they have no affiliation with or involvement in any organization or entity with any financial interest, or non- financial interest in the subject matter or materials dismissed in this manuscript.

The authors' contribution is as follows: Concept, design, collection, drafting article, preliminary data analysis: B. Ghorbani Taghlidabad; Data analysis and interpretation: R. Tasbihsazan Mashhadi; and Critical revision of article: B. Ghorbani Taghlidabad and $\mathrm{R}$. Tasbihsazan Mashhadi.

\section{References}

Ahadi, B., \& Basharpoor, S. (2010). Relationship between sensory processing sensitivity, personality dimensions, and mental health. Journal of Applied Sciences, 10(7), 570-4. [DOI:10.3923/jas.2010.570.574]

Almquist, E., Tornblom, H., \& Simren, M. (2016). Practical management of irritable bowel syndrome: A clinical review. Minerva Gastroenterologica e Dietologica, 62(1), 30-48. [PMID]

Aron, E. N., \& Aron, A. (1997). Sensory-processing sensitivity and its relation to introversion and emotionality. Journal of Personality and Social Psychology, 73(2), 345-68. [DOI:10.1037/0022-3514.73.2.345] [PMID]

Benham, G. (2006). The highly sensitive person: Stress and physical symptom reports. Personality and Individual Differences, 40(7), 1433-40. [DOI:10.1016/j.paid.2005.11.021.]

Bentler, P. M. (1989). EQS structural equation program manual. Los Angeles: BMDP Statistical Software.

Boyce, W. T., Chesney, M., Alkon, A., Tschann, J. M., Adams, S., Chesterman, B., et al. (1995). Psychobiologic reactivity to stress and childhood respiratory illnesses: Results of two prospective studies. Psychosomatic Medicine, 57(5), 411-22. [DOI:10.1097/00006842-199509000-00001] [PMID] 
Carver, C. S., \& White, T. L. (1994). Behavioral inhibition, behavioral activation, and affective responses to impending reward and punishment: The BIS/BAS scales. Journal of Personality and Social Psychology. 67(2), 319-33. [DOI:10.1037/0022-3514.67.2.319]

Cheung, G., W., \& Lau, R. S. (2007). Testing mediation and suppression effects of latent variables; Bootstrapping with structural equation models. Organizational Research Methods, 11(2), 296-325. [DOI:10.1177/1094428107300343]

Chey, W. D., Kurlander, J. \& Eswaran, S. (2015). Irritable bowel syndrome - A clinical review. The Journal of American Medical Association, 313(9), 949-58. [DOI:10.1001/jama.2015.0954] [PMID]

Cohen, S., Kamarch, T., \& Mermelstein, R. (1983). A global measure of perceived stress. Journal of Health and Social Behavior, 24(4), 385-96. [DOI:10.2307/2136404]

Cole, D. A. (1987). Utility of confirmatory factor analysis in test validation research. Journal of Consulting and Clinical Psychology, 55(4), 584-94. [DOI:10.1037/0022-006X.55.4.584] [PMID]

Dickhaus, B., Mayer, E. A., Firooz, N., Stains, J., Conde, F., Olivas, T. I., Fass, R., et al. (2003). Irritable bowel syndrome patients show enhanced modulation of visceral perception by auditory stress. American Journal of Gastroenterology, 98, 135-43. [DOI:10.1111/j.1572-0241.2003.07156.x]

Drossman, D. A., Lesserman, J., Nachman, G., Li, Z. M., Gluck, H., Toomey, T. C. et al. (1990). Sexual and physical abuse in women with functional or organic gastrointestinal disorders. Annals of Internal Medicine, 113(11), 828-33. [DOI:10.7326/0003-4819-113-11-828] [PMID]

Dunn, W. (2001). The sensations of everyday life: Empirical, theoretical, and pragmatic considerations. American Journal of Occupational Therapy, 55(6), 608-s20. [DOI:10.5014/ ajot.55.6.608] [PMID]

Egger, G. J., Binns, A. F., \& Rossner, S. R. (2009). The emergence of lifestyle medicine as a structured approach for management of chronic disease. Medical Journal of Australia, 190(3),143-5. [PMID]

Evers, A., Rasche, J., \& Schabracq, M. J. (2008). High sensoryprocessing sensitivity at work. International Journal of Stress Management, 15(2), 189-98. [DOI:10.1037/1072-5245.15.2.189]

Eysenck, H. J. (1990). Biological dimensions of personality. In L. A. Pervin (Ed.), Handbook of Personality (pp. 224-276). New York: Guilford Press.

Gannon, L., Banks, J., Shelton, D., \& Luchetta, T. (1989). The mediating effects of psychophysiological reactivity and recovery on the relationship between environmental stress and illness. Journal of Psychosomatic Research, 33(2), 167-75. [DOI:10.1016/0022-3999(89)90044-5]

Gerstenberg, F. X. R. (2012). Sensory-processing sensitivity predicts performance on a visual search task followed by an increase in perceived stress. Personality and Individual Differences, 53(4), 496-500. [DOI:10.1016/j.paid.2012.04.019]

Gray J. A. (1981) A Critique of Eysenck's Theory of Personality. In H. J. Eysenck (Ed.) A Model for Personality (pp. 246276). Berlin: Springer. [DOI:10.1007/978-3-642-67783-0_8]

Hofmann, S. G., \& Bitran, S. (2007). Sensory-processing sensitivity in social anxiety disorder: Relationship to harm avoid- ance and diagnostic subtypes. Journal of Anxiety Disorders, 21(7), 944-54. [DOI:10.1016/j.janxdis.2006.12.003] [PMID] [PMCID]

Hoyle, R. H. (1995). The structural equation modeling approach: Basic concepts and functional issues. In R. H. Hoyle (Ed.) Structural Equation Modelling: Concepts, Issues, and Applications (pp. 1-16). SAGE: London.

Joreskog, K. G., Sorbom, D. (1989). Lisrel 7, A guide to the program and applications. Chicago: SPSS.

Kagan, J. (1994). Galen's prophecy: Temperament in human nature. New York: Basic Books.

Liss, M., Timmel, L., Baxley, K., \& Killingsworth, P. (2005) Sensory processing sensitivity and its relation to parental bonding, anxiety, and depression. Personality and Individual Differences, 39(8), 1429-39. [DOI:10.1016/j.paid.2005.05.007.]

Lovell, R. M., \& Ford, A. C., (2012). Global prevalence of and risk factors for irritable bowel syndrome: A meta-analysis. Clinical Gastroenterology and Hepatology , 10(7), 712-21. [DOI:10.1016/j.cgh.2012.02.029] [PMID]

MacCallum, R. C., \& Austin, J. T. (2000). Applications of structural equation modeling in psychological research. Annual Review of Psychology, 51, 201-26. [DOI:10.1146/annurev. psych.51.1.201] [PMID]

Mayer, E. A., Naliboff, B. D., Chang, L., \& Coutinho, S.V (2001). V. Stress and irritable bowel syndrome. Journal of Physiology-Gastrointestinal and Liver Physiology, 280(4), 51924. [DOI:10.1152/ajpgi.2001.280.4.G519] [PMID]

Meleine, M., \& Matricon, J. (2014). Gender-related differences in irritable bowel syndrome: potential mechanisms of sex hormones. World Journal of Gastroenterology, 20 (22), 6725-43. [DOI:10.3748/wig.v20.i22.6725] [PMID] [PMCID]

Mertz, H., Morgan, V., Tanner, G., Pickens, D., Price, R., Shyr, Y., et al. (2000). Regional cerebral activation in irritable bowel syndrome and control subjects with painful and nonpainful rectal distention. Gastroenterology, 118(5), 842-8. [DOI:10.1016/S0016-5085(00)70170-3]

Meyer, B., Ajchenbrenner, M., \& Bowles, D. P. (2005). Sensory sensitivity, attachment experiences, and rejection responses among adults with borderline and avoidant features. Journal of Personality Disorders, 19(6), 641-58. [DOI:10.1521/ pedi.2005.19.6.641] [PMID]

Miller, L. H., \& Smith, A. D. (1988). The miller-smith lifestyle assessment inventory. Bookline: Biobehavioral Associates.

Mulaik, S. A., James, M. R., Van Alstine, J., Bennett, N., Lind S., \& Stilwell, C. D. (1989). Evaluation of goodness of fit indices for structural equation models. Psychological Bulletin, 105(3), 430-45. [DOI:10.1037/0033-2909.105.3.430]

Naliboff, B. D., Derbyshire, S. W., Munakata, J., Berman, S., Mandelkern, M., Chang, L., et al. (2001). Cerebral activation in irritable bowel syndrome patients and control subjects during rectosigmoid stimulation. Psychosomatic Medicine, 63(3), 365-75. [DOI:10.1097/00006842-200105000-00006] [PMID]

Neal, J., Edelmann, R. J., \& Glachan, M., (2002). Behavioral inhibition and symptoms of anxiety and depression: Is there a specific relationship with social phobia? British Journal of 
Clinical Psychology, 41 (Pt4), 361-74. [DOI:10.1348/01446650 2760387489] [PMID]

Smolewska, K. A., McCabe, S. B., \& Woody, E. Z. (2006). A psychometric evaluation of the Highly Sensitive Person Scale: The components of sensory-processing sensitivity and their relation to the BIS/BAS and Big Five. Personality and Individual Differences, 40(6), 1269-79. [DOI:10.1016/j. paid.2005.09.022]

Sood, R., Law, G. R., \& Ford, A. C. (2014). Diagnosis of IBS: Symptoms, symptom-based criteria, biomarkers or psychomarkers? Nature Reviews Gastroenterology and Hepatology, 11, 683-91. [DOI:10.1038/nrgastro.2014.127]

Tabachnick, B. G. \& Fidell, L. S. (1996). Using multivariate statistics. New York: Harper Collins College.

Teo, T., \& Noyes, J. (2014). Explaining the intention to use technology among pre-service teachers: A multi-group analysis of the Unified Theory of Acceptance and Use of Technology. Interactive Learning Environments, 22(1), 51-66. [DOI:10.1080 /10494820.2011.641674]

Tucker, L. R., \& Lewis, C. (1973). A reliability coefficient for maximum likelihood factor analysis. Psychometrika, 38(1), 1-10. [DOI:10.1007/BF02291170]

Wood, J. D. (2001). Enteric nervous system, serotonin and the irritable bowel syndrome. Current Opinion in Gastroenterology, 17(1), 91-7. [DOI:10.1097/00001574-200101000-00017] [PMID] 
